\title{
Monitoramento da variabilidade genética de pacu, Piaractus mesopotamicus, do programa de aumento de estoque do rio Paranapanema
}

\author{
[Monitoring of the genetic variability of pacu, Piaractus mesopotamicus, of the stock enhancement \\ program of the Paranapanema River] \\ J.A. Povh ${ }^{1}$, R.P. Ribeiro ${ }^{2}$, N.M. Lopera-Barrero ${ }^{2}$, P.C. Gomes ${ }^{2}$, D.V. Blanck ${ }^{3}$, L. Vargas $^{2}$, \\ C.B. Jacometo ${ }^{2}$, T.S. Lopes ${ }^{4}$ \\ ${ }^{1}$ Universidade Federal de Mato Grosso \\ Rod. Rondonópolis - Guiratinga, km 6 (MT-270) \\ 78735-910 - Rondonópolis, MT \\ ${ }^{2}$ Universidade Estadual de Maringá - Maringá, PR \\ ${ }^{3}$ Universidade Federal de São Carlos - São Carlos, SP \\ ${ }^{4}$ Centro de Aqüicultura - UNESP - Jaboticabal, SP
}

\begin{abstract}
RESUMO
Avaliou-se a variabilidade genética dos estoques de reprodutores e dos peixes jovens de Piaractus mesopotamicus de três pisciculturas do estado do Paraná, utilizadas no programa de aumento de estoque de peixes no rio Paranapanema. Foi utilizado o marcador RAPD para avaliar as amostras do estoque de reprodutores e dos peixes jovens das pisciculturas de Palotina, Cambará e Andirá. A porcentagem de fragmentos polimórficos e o índice de diversidade genética de Shannon dos estoques de reprodutores variaram de $75,0 \%$ a $71,4 \%$ e de 0,434 a 0,376 , respectivamente. Os peixes jovens das pisciculturas apresentaram valores mais elevados para ambos os parâmetros, com exceção da piscicultura de Palotina, na qual o índice de diversidade genética de Shannon foi semelhante. Os estoques de reprodutores apresentaram alta variabilidade genética, e esta foi mantida nos peixes jovens.
\end{abstract}

Palavras-chave: Piaractus mesopotamicus, peixes jovens, estoque de reprodutores, RAPD, variabilidade genética

\begin{abstract}
The genetic variability of broodstocks and juveniles of Piaractus mesopotamicus raised in three hatchery stations in Parana state, that were used in the fish stock enhancement program of the Paranapanema River, was estimated. The RAPD marker was used to evaluate samples taken from broodstocks and juveniles in the hatchery stations of Palotina, Cambará, and Andirá cities. The percentage of polymorphic fragments and the Shannon genetic diversity index of broodstocks ranged from $75.0 \%$ to $71.4 \%$ and from 0.434 to 0.376 , respectively. The juveniles of the hatchery stations presented higher values for both parameters, except in the hatchery station of Palotina in which the Shannon genetic diversity index was similar. The broodstocks presented high genetic variability, and this was maintained in the juveniles.
\end{abstract}

Keywords: Piaractus mesopotamicus, juveniles, broodstock, RAPD, genetic variability

\section{INTRODUÇÃO}

Os programas de aumento de estoque de peixes têm sido utilizados há mais de três décadas para a recuperação dos estoques nativos de vários rios brasileiros (Povh, 2008a). Segundo a Agência
Estadual de Notícias - AEN (Soltura..., 2007), mais de 9,8 milhões de peixes jovens foram soltos pelo programa de Reposição Pesqueira dos Rios Paranaenses desenvolvido pela Secretaria de Estado da Agricultura e Abastecimento do Estado do Paraná, sendo que entre as últimas

Recebido em 26 de fevereiro de 2009

Aceito em 15 de outubro de 2009

E-mail: jayme.peixegen@gmail.com 
solturas de peixe no rio Paranapanema, destacase a de 610 mil peixes jovens de pacu (Piaractus mesopotamicus), curimba (Prochilodus lineatus) e piapara (Leporinus elongatus).

Características como o elevado valor comercial, adaptação à alimentação artificial e facilidade de obtenção de larvas por meio de reprodução induzida contribuíram para tornar a espécie $P$. mesopotamicus o segundo peixe nativo mais cultivado no Brasil (Estatística..., 2008). Essas características, associadas ao fato de que atualmente essa espécie raramente é encontrada no rio Paranapanema (Britto et al., 2003), tornaram a espécie $P$. mesopotamicus uma das mais utilizadas em programas de aumento de estoque de peixes deste rio, como se pode observar nos dados divulgados pela AEN (Agência..., 2007) do Estado do Paraná.

O manejo reprodutivo dos estoques de reprodutores pode diminuir a variabilidade genética dos peixes jovens que são soltos nos rios (Povh et al., 2008b), levando à diminuição da resistência a doenças (Taniguchi, 2003) e da capacidade de adaptação a diferentes condições ambientais (Povh et al., 2008). Nesse contexto, o monitoramento genético dos estoques de reprodutores e dos peixes jovens que serão soltos nos rios é fundamental para a viabilidade dos programas de aumento de estoque de peixes e para evitar efeitos adversos na ictiofauna (Lopera-Barrero et al., 2006; Sirol e Britto, 2006; Povh et al., 2008ab). Os marcadores moleculares são ferramentas importantes para o monitoramento genético (Ortega-Villaizán Romo et al., 2006; Povh et al., 2008a), sendo o marcador RAPD muito utilizado para esse propósito em várias espécies de peixes (Almeida et al., 2003; Leuzzi et al., 2004; Sofia et al., 2006).

O objetivo do presente estudo foi avaliar a variabilidade genética de estoques de reprodutores e de peixes jovens da espécie $P$. mesopotamicus de três estações de pisciculturas utilizadas em um programa de aumento de estoques de peixes do rio Paranapanema.

\section{MATERIAL E MÉTODOS}

Foram colhidas amostras dos estoques de reprodutores e de peixes jovens da espécie $P$. mesopotamicus, entre 30 a 40 dias de idade, destinados à soltura no rio Paranapanema, das pisciculturas de Palotina, Cambará e Andirá, todas localizadas no Estado do Paraná. As três pisciculturas são utilizadas pelo governo do Estado em um programa de aumento do estoque de peixes do rio Paranapanema, um importante afluente do rio Paraná. Foram analisadas 60 amostras de cada piscicultura, 30 do estoque de reprodutores e 30 de peixes jovens.

A extração de DNA das amostras foi realizada a partir de fragmentos de nadadeira caudal, utilizando a metodologia descrita por Aljanabi e Martinez (1997), modificada por Lopera-Barrero et al. (2008). O DNA foi quantificado por comparação com concentrações de DNA fago $\lambda$ conhecidas em gel de agarose $1 \%$, sendo a eletroforese realizada com tampão $1 \mathrm{X}$ TAE (40mM de Tris-acetato e $1 \mathrm{mM}$ de EDTA) por uma hora a 70 volts.

O DNA foi amplificado em um volume de reação de $15 \mu$, no qual se utilizou tampão $1 \mathrm{X}$ Tris-KCl, 2,0mM de $\mathrm{MgCl}_{2}, 0,46 \mu \mathrm{M}$ de primer, $0,2 \mathrm{mM}$ de cada dNTP, uma unidade de Taq DNA polimerase e 10ng de DNA. Inicialmente, o DNA foi desnaturado a $94^{\circ} \mathrm{C}$ por quatro minutos e, em seguida, foram realizados 40 ciclos, cada um consistindo de um minuto de desnaturação a $94^{\circ} \mathrm{C}$, um minuto e 30 segundos de anelamento a $40^{\circ} \mathrm{C}$ e dois minutos de extensão a $72^{\circ} \mathrm{C}$. Posteriormente, realizou-se uma extensão final a $72^{\circ} \mathrm{C}$ por sete minutos. As reações foram amplificadas em termociclador Eppendorf Mastercycler Gradient, sendo avaliados 60 primers do kit OPA, OPX e OPW da Operon ${ }^{1}$, dos quais foram selecionados os que produziram um bom padrão de amplificação. A eletroforese foi realizada em tampão $0,5 \mathrm{X}$ TBE $(45 \mathrm{mM}$ de Tris-Borato e $1 \mathrm{mM}$ de EDTA) por quatro horas a 70 volts.

O gel de quantificação do DNA e os géis de amplificação foram visualizados sob a radiação ultravioleta após exposição destes ao brometo de etídio $(0,5 \mu \mathrm{g} / \mathrm{mL})$ por uma hora. Posteriormente, a imagem foi fotografada com o programa Kodak EDAS-290².

O tamanho dos fragmentos foi determinado com padrão de peso molecular 100 pb DNA ladder. A

${ }^{1}$ Operon Technologies, Alemanha

${ }^{2}$ Kodak 1D Image Analysis 3.5 
variabilidade genética foi estimada pela porcentagem de fragmentos polimórficos e índice de diversidade genética de Shannon, obtidos pelo programa PopGene 1.31 (Yeh et al., 1999).

\section{RESULTADOS E DISCUSSÃO}

Os primers selecionados

OPA16 (5'-AGCCAGCGAA-3'),

OPW01 (5'-CTCAGTGTCC-3'),

OPW03 (5'-GTCCGGAGTG-3'),

OPW08 (5'-GACTGCCTCT-3'),

OPW19 (5'-CAAAGCGCTC-3'),

OPX01 (5'-CTGGGCACGA-3') e

OPX03 (5'-TGGCGCAGTG-3') produziram 75 fragmentos, com tamanho variando de 210 a $1200 \mathrm{pb}$.

A porcentagem de fragmentos polimórficos foi mais alta para o estoque de reprodutores da piscicultura de Palotina em relação aos de Cambará e Andirá (Fig. 1). Da mesma forma, o índice de diversidade genética de Shannon foi mais elevado no estoque de reprodutores da piscicultura de Palotina (Fig. 2). Essa diferença entre os estoques de reprodutores pode ser atribuída ao efeito fundador e ao manejo reprodutivo adotado nas pisciculturas. Contudo, os resultados mostram alta variabilidade genética nos três estoques de reprodutores, indicando que o manejo reprodutivo utilizado na formação desses estoques manteve alta variabilidade genética.
Na piscicultura de Palotina, foi obtida a mesma porcentagem de fragmentos polimórficos para o estoque de reprodutores e para os peixes jovens, e nas pisciculturas de Cambará e Andirá os peixes jovens apresentaram porcentagem mais alta (Fig. 1). Com exceção da piscicultura de Palotina, em que os peixes jovens e o estoque de reprodutores tiveram semelhante índice de diversidade genética de Shannon, nas pisciculturas de Cambará e Andirá os peixes jovens apresentaram índice mais alto (Fig. 2). Estes resultados mostram maior variabilidade genética nos peixes jovens em relação ao estoque de reprodutores nas pisciculturas de Cambará e Andirá, e semelhante variabilidade genética entre os peixes jovens e o estoque de reprodutores na piscicultura de Palotina. Dessa forma, o manejo reprodutivo adotado nas três pisciculturas não conduziu a uma diminuição da variabilidade genética nos peixes jovens.

Produzir peixes jovens com alta variabilidade genética não depende apenas de se ter um estoque de reprodutores com essa característica. Os resultados do presente trabalho mostram que o manejo reprodutivo pode manter ou até mesmo maximizar a variabilidade genética nos peixes jovens. No entanto, este também pode promover diminuição da variabilidade genética (Moreira et al., 2007), e em apenas uma geração, como observaram Porta et al. (2006), após analisarem duas gerações de estoque de reprodutores de Solea senegalensis.

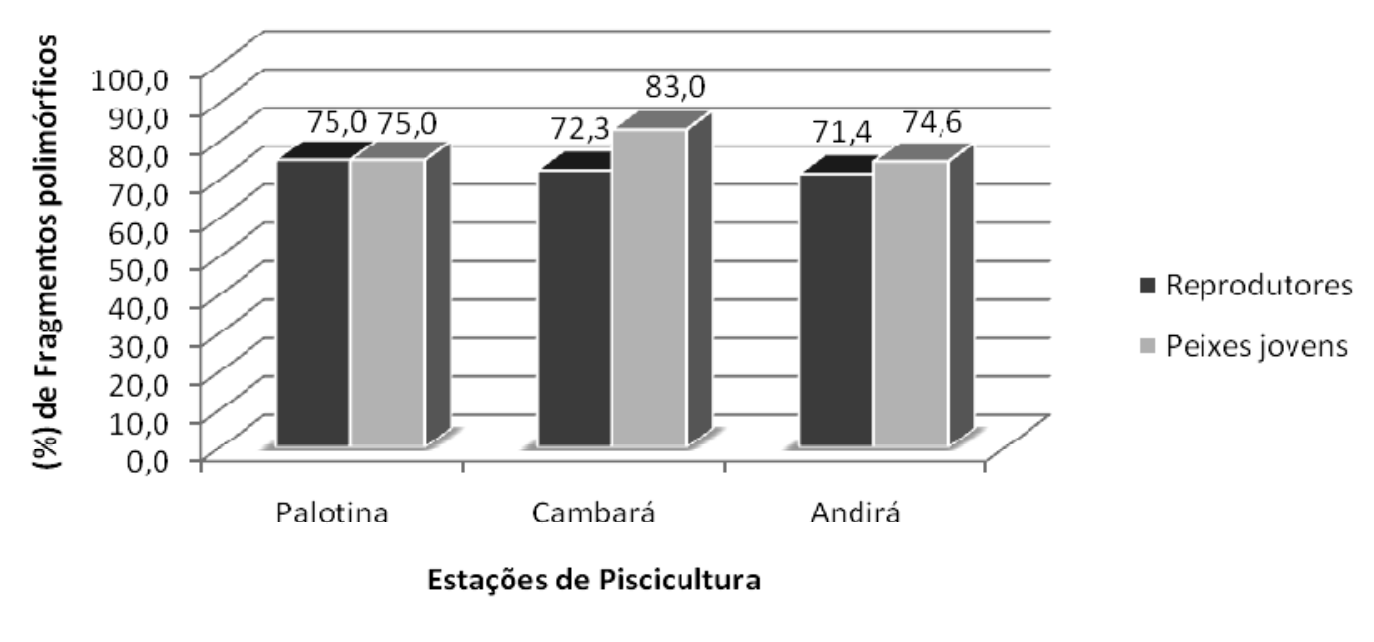

Figura 1. Porcentagem de fragmentos polimórficos obtido para os estoques de reprodutores e para peixes jovens de Piaractus mesopotamicus das pisciculturas de Palotina, Cambará e Andirá. 


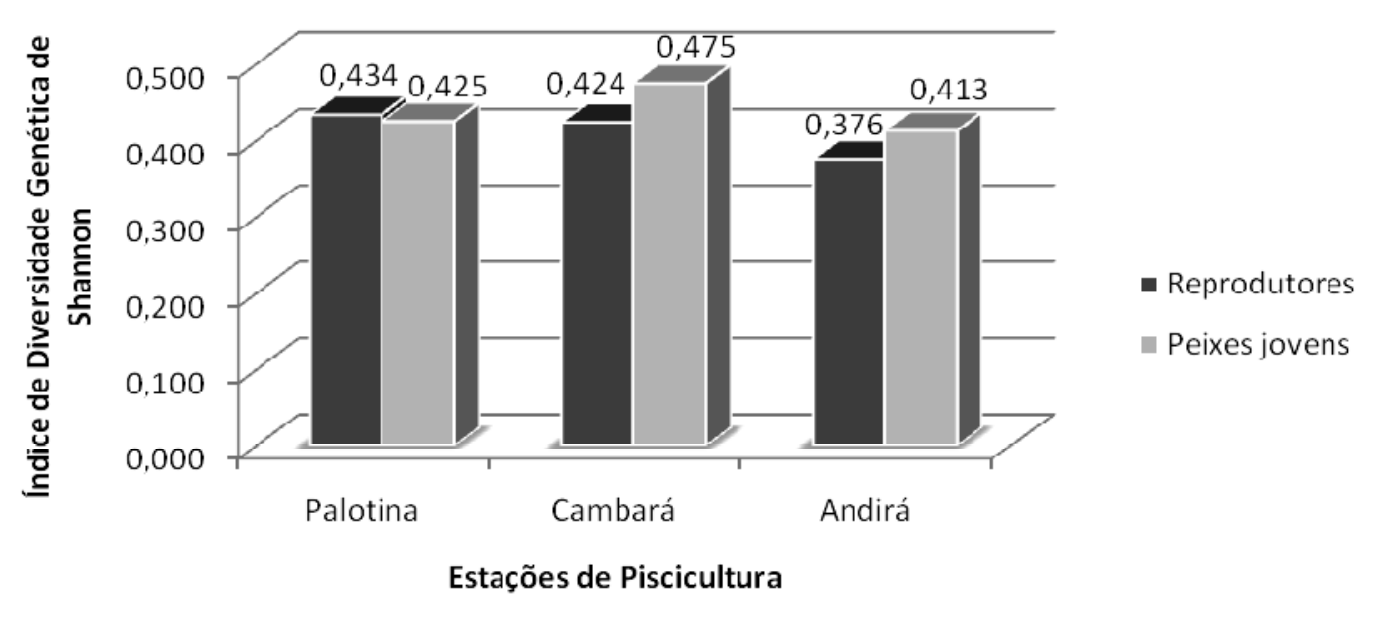

Figura 2. Índice de diversidade genética de Shannon obtido para os estoques de reprodutores e para os peixes jovens de Piaractus mesopotamicus das pisciculturas de Palotina, Cambará e Andirá.

Entre os fatores que contribuem para a diminuição da variabilidade genética, destacamse a endogamia (Melo et al., 2006; Moreira et al., 2007), a reprodução de um pequeno número de reprodutores e a seleção não intencional, a qual se caracteriza pela seleção de reprodutores com base em uma determinada característica, sem pretensões de melhoramento genético como, por exemplo, de peixes maiores ou menores, e pela não utilização de todo o período reprodutivo (Povh et al., 2008a). Esses fatores são responsáveis pela diminuição da variabilidade genética de estoques de reprodutores (Wasko et al., 2004; Barroso et al., 2005; Povh et al., 2005) e de peixes jovens destinados à soltura no ambiente (Sekino et al., 2002; Gomes et al., 2008; Ortega- Villaizán Romo et al., 2006).

A diminuição da variabilidade genética pode tornar um programa de aumento de estoque de peixes ineficiente, com baixa sobrevivência dos peixes jovens no ambiente, e proporcionar impactos genéticos irreversíveis na ictiofauna (Povh et al., 2008a). Dessa forma, o monitoramento da variabilidade genética dos estoques de reprodutores e dos peixes jovens que serão liberados nos rios é fundamental para um programa de aumento de estoque de peixes.

Vários fatores que impactam o ecossistema devem ser considerados para que haja sucesso em um programa de aumento de estoque de peixes e não ocorram efeitos adversos na ictiofauna. Portanto, medidas conjuntas de conservação da diversidade genética e do ecossistema aquático são necessárias para que esses programas tenham sucesso.

Os resultados do presente estudo indicam que os estoques de reprodutores avaliados apresentaram alta variabilidade genética, e que esta foi mantida nos peixes jovens. Além disso, o marcador RAPD mostrou ser eficiente para o monitoramento genético de um programa de aumento de estoque de peixes.

\section{REFERÊNCIAS BIBLIOGRÁFICAS}

ALJANABI, S.M.; MARTINEZ, I. Universal and rapid salt-extraction of high quality genomic DNA for PCR-based techniques. Nucl. Acids. Res., v.25, p.4692-4693, 1997.

ALMEIDA, F.S.; SODRÉ, L.M.K.; CONTEL, E.P.B. Population structure analysis of Pimelodus maculatus (Pisces, Siluriformes) from the Tietê and Paranapanema Rivers (Brazil). Genet. Mol. Biol., v.26, p.301-305, 2003.

BARROSO, R.M.; HILSDORF, A.W.S.; MOREIRA, H.L.M. et al. Genetic diversity of wild and cultured populations of Brycon opalinus (Cuvier, 1819) (Characiforme, Characidae, Bryconiae) using microsatellites. Aquaculture, v.247, p.51-65, 2005.

BRITTO, S.G.C.; SIROL, R.N.; VIANNA, N.C. et al. (Eds). Peixes do Rio Paranapanema. São Paulo: Duke Energy Internacional Geração Paranapanema, 2003. 112p. 
ESTATÍSTICA da pesca 2006 Brasil: grandes regiões e unidades da federação. Brasília: IBAMA, 2008. 174p.

GOMES, P.C.; RIBEIRO, R.P.; LOPERABARRERO, N.M. et al. Diversidade genética de três estoques de piapara (Leporinus elongatus), utilizando RAPD. Acta Sci. Anim. Sci., v.30, p.241-247, 2008.

LEUZZI, M.S.P.; ALMEIDA, F.S.; ORSI, M.L. et al. Analysis by RAPD of the genetic structure of Astyanax altiparanae (Pisces, Characiformes) in reservoirs of the River Paranapanema. Genet. Mol. Biol., v.27, p.355-362, 2004.

LOPERA-BARRERO, N.M.; POVH, J.A.; RIBEIRO, R.P. et al. Comparación de protocolos de extracción de ADN con muestras de aleta y larva de peces: extracción modifi cada con cloruro de sodio. Cienc. Inv. Agr., v.35, p.77-86, 2008.

LOPERA-BARRERO, N.M.; RIBEIRO, R.P.; SIROL, R.N. et al. Genetic diversity in piracanjuba populations (Brycon orbignyanus) with the RAPD (Random Amplified Polimorphic DNA) markers. J. Anim Sci., v.84, p.170-170, 2006.

MELO, D.C.; OLIVEIRA, D.A.A.; RIBEIRO, L.P. et al. Caracterização genética de seis plantéis comerciais de tilápia (Oreochromis) utilizando marcadores microssatélites. Arq. Bras. Med. Vet. Zootec., v.58, p.87-93, 2006.

MOREIRA, A.A.; HILSDORF, A.W.S.; SILVA, J.V. et al. Variabilidade genética de duas variedades de tilápia nilótica por meio de marcadores microssatélites. Pesq. Agropec. Bras., v.42, p.521-526, 2007.

ORTEGA-VILLAIZÁN ROMO, M.M.; ARITAKI, M.; TANIGUCHI, N. Pedigree analysis of recaptured fish in the stock enhancement program of spotted halibut Verasper variegates. Fish. Sci., v.72, p.48-52, 2006.

PORTA, J.; PORTA, J.M.; MARTÍNEZRODRÍGUEZ, G. et al. Genetic structure and genetic relatedness of a hatchery stock of Senegal sole (Solea senegalensis) inferred by microsatellites. Aquaculture, v.251, p.46-55, 2006

POVH, J.A.; LOPERA-BARRERO, N.M.; RIBEIRO, R.P. et al. Importancia del monitoreo genético de programas de repoblamiento de peces mediante marcadores moleculares. Cien. Inv. Agr., v.35, p.5-15, 2008a.

POVH, J.A.; MOREIRA, H.L.M.; RIBEIRO, R.P. et al. Estimativa da variabilidade genética em tilápia do Nilo (Oreochromis niloticus) com a técnica de RAPD. Acta Sci. Anim. Sci., v.27, p.1$10,2005$.

POVH, J.A.; RIBEIRO, R.P.; SIROL, R.N. et al Diversidade genética de pacu do rio Paranapanema e do estoque de um programa de repovoamento. Pesq. Agropec. Bras., v.43, p.201-206, 2008b.

SEKINO, M.; HARA, M.; TANIGUCHI, N. Loss of microsatellite and mitochondrial DNA variation in hatchery strains of Japanese flounder Paralichthys olivaceus. Aquaculture, v.213, p.101-122, 2002.

SIROL, R.N.; BRITTO, S.G. Conservação e manejo da ictiofauna: repovoamento. In: NOGUEIRA, M.G.; HENRY, R.; JORCIN, A. (Eds.). Ecologia de reservatórios: impactos potenciais, ações de manejo e sistemas em cascatas. São Carlos: RiMA, 2006. p.275-284.

SOFIA, S.H.; SILVA, C.R.M.; GALINDO, B.A. et al. Population genetic structure of Astyanax scabripinnis (Teleostei, Characidae) from an urban stream. Hydrobiologia, v.553, p.245-254, 2006.

SOLTURA de peixes nos rios do Paraná, 2007. Curitiba: Agência Estadual de Notícias. Disponível em: $<$ http://www.agenciadenoticias.pr.gov.br $>$. Acessado em: 18 ago. 2007.

TANIGUCHI, N. Genetic factors in broodstock management for seed production. Rev. Fish Biol. Fish., v.13, p.175-185, 2003.

WASKO, A.P.; MARTINS, C.; OLIVEIRA, C. et al. Genetic monitoring of the Amazonian fish matrinchã (Brycon cephalus) using RAPD markers: insights into supportive breeding and conservation programmes. J. Appl. Ichthyol., v.20, p.48-52, 2004.

YEH, F.C.; BOYLE, T.Y.Z.; XIYAN, J.M. (Eds.). POPGENE Version 131: Microsoft Window-based freeware for population genetic analysis. Alberta, Can: University of Alberta and Center for International Forestry Research, 1999. 